$\begin{array}{llll}\text { Submission: 20/04/2020; } & 1^{\text {st }} \text { round notif.: 27/08/2020; } & \text { New version: 13/10/2020; } & 2^{\text {nd }} \text { round notif.: 07/12/2020; } \\ \text { Camera ready: 13/12/2020; } & \text { Edition review: 15/12/2020; } & \text { Available online: 20/12/2020; } & \text { Published: 20/12/2020; }\end{array}$

\title{
Habilidades Socioemocionais e Tecnologias Educacionais: Revisão Sistemática de Literatura
}

\author{
Title: Soft Skills and Educational Technologies: Systematic Literature Review
}

\author{
Fabiana Maris Versuti \\ USP - RP \\ fabiana_versuti@usp.br \\ Flavio Pinheiro Martins \\ FEA-RP/USP \\ fpmartins@usp.br
}

\author{
Rafael Lima Dalle Mulle \\ $U S P$ - RP \\ rafadmulle@gmail.com \\ Deise Aparecida Peralta \\ UNESP-FEIS \\ deise.peralta@unesp.br
}

\author{
Carlos Antônio Rodrigues \\ Guerreiro \\ $U S P$ - RP \\ guerreirocar@usp.br
}

\section{Resumo}

O presente artigo realizou uma revisão sistemática de literatura relacionando tecnologias educacionais e habilidades socioemocionais. Para isto, foi utilizada a plataforma de evidencias SUMARIZE. Foram realizadas buscas em 13 bases de dados: 238 artigos foram encontrados e após leitura dos resumos estruturados (screening), 25 artigos foram selecionados para serem lidos na íntegra, ao final do processo restaram 10 artigos aceitos para revisão sistemática. O conceito de tecnologia educacional aqui considerado é o de um escopo amplo: toma por base abordagens "usuais" como aquelas relacionadas a digitalização (ambientes virtuais por exemplo), bem como a perspectiva ampliada sobre treinamentos e práticas para agentes educacionais. A síntese dos estudos permite observar um campo de intersecção dos saberes ainda em desenvolvimento com um espectro diverso de abordagens. Nota-se também a amplitude do conceito de tecnologia educacional tomado aqui como base e que transita de abordagens usuais como a dos ambientes virtuais de aprendizagem até a validação de escalas e treinamentos específicos para agentes educacionais. Assim sendo, verifica-se uma polissemia de sentidos acerca da temática, que gera obstáculos à produção baseada em evidências. Os achados deste estudo evidenciam que o aumento no discurso das políticas públicas educacionais acerca da relevância do desenvolvimento de habilidades socioemocionais consideradas cruciais à promoção do sucesso na escola e na vida e ao desenvolvimento integral do indivíduo se deu de forma desarticulada com os avanços de investigações na área, e reiteram o distanciamento entre o conhecimento acadêmico e cotidiano escolar. Sendo assim, estudos desta natureza, com definição clara dos construtos não só são pertinentes, como são urgentes.

Palavras-chave: Tecnologias Educacionais; Tecnologia da Informação e Comunicação; Tecnologia Digital da Informação e Comunicação; Habilidades Socioemocionais; Competências Socioemocionais.

\begin{abstract}
This article carried out a systematic review of the literature relating educational technologies and socio-emotional skills, for this, the evidence platform SUMARIZE was used. Searches were conducted in 13 databases, in which 238 articles were found, after reading a summary of these, 25 articles were selected for full reading, in which 10 were accepted for systematic review. The concept of educational technology considered here is that of a broad scope: it is based on "usual" approaches such as those related to digitization (virtual environments for example), as well as the expanded perspective on training and practices for educational agents. The synthesis of the studies allows us to observe a diverse spectrum of approaches which is still in development. It is also noted the breadth of the concept of educational technology taken here as a basis and which moves from usual approaches such as virtual learning environments to the validation of scales and specific training for educational agents. Therefore, there is a polysemy of meanings about the theme, which creates obstacles to evidence-based production. The findings of this study show
\end{abstract}

Versuti, F. M., Mulle, R. L. D., Guerreiro, C. A. R., Martins, F. P., \& Peralta, D. A. (2020). Soft Skills and Educational Technologies: Systematic Literature Review (Habilidades Socioemocionais e Tecnologias Educacionais: Revisão Sistemática de Literatura). Brazilian Journal of Computers in Education (Revista Brasileira de Informática na Educação - RBIE), 28, 1086-1104. DOI: 10.5753/RBIE.2020.28.0.1086 
that the increase in the discourse of public educational policies about the relevance of the development of socioemotional skills considered crucial to the promotion of success in school and in life and to the integral development of the individual occurred in a disarticulated way with the advances of investigations in area, and reiterate the gap between academic and everyday school knowledge. Therefore, studies of this nature, with a clear definition of the constructs are not only pertinent, but also urgent.

Keywords: Educational Technologies; Information and communication technology; Digital Information and Communication Technology; Socio-emotional skills; Socioemotional Skills.

\section{Introdução}

Há, na atualidade, um aumento nas investigações acerca da relevância do desenvolvimento de habilidades socioemocionais no contexto educacional, tidas como centrais nas políticas curriculares contemporâneas no Brasil e consideradas cruciais à promoção do sucesso na escola e na vida e ao desenvolvimento integral do indivíduo (Abed, 2016; Marin \& Fava, 2016; Petrucci et al., 2016; Ciervo \& Silva, 2019). Este aumento no interesse e no número de estudos foi acompanhado, em alguns países, por iniciativas legislativas para sistematizar e uniformizar práticas no desenvolvimento dessas habilidades bem como para traduzir a narrativa em prática no dia-a-dia escolar (Coelho, Marchante, Sousa \& Romão, 2016; Ciervo \& Silva, 2019).

O conceito socioemocional está inserido no estudo das habilidades sociais, relacionando-se com repertórios da gestão de relações interpessoais e afetivas, na interface com a forma como as pessoas percebem, sentem e expressam a interação entre situações contingenciais e de comportamentos (Bolsoni-Silva, 2002; Caballo, 2014). Nessa perspectiva preconiza-se que os comportamentos podem se modificar em função do meio social e são passíveis de intervenção específica, visando a uma melhor adaptação da interação da pessoa com o contexto social (Lopez, 2008).

Assim o sendo, as habilidades socioemocionais podem ser ensinadas e aprendidas. São elas um dos fatores de proteção para o desenvolvimento do indivíduo e, seu ensino, uma das estratégias advogadas para promoção de sucesso estudantil e de reformas escolares eficazes. A melhora dos resultados acadêmicos seria fruto do desenvolvimento da autorregulação, da melhora nas relações entre escola e comunidade, da redução de conflitos entre alunos e melhora a disciplina da sala de aula, promovendo maior sensação de bem-estar social (Mcclelland, Tominey, Schimitt e Duncan, 2017).

O conceito "habilidades socioemocionais" tem sido usado prescindindo de maiores esclarecimentos teóricos-conceituais, encontrando-se em uma zona cinza na qual ainda é alvo de tentativas de definição. Não obstante, tal incerteza não tem impedido que o conceito seja aplicado a políticas, programas e projetos educacionais. Dessa forma, faz-se urgente lançar visibilidade ao conceito e a suas formas de definição para que não reste ao professor a interpretação e implementação de um conceito sobre o qual não existe um consenso. Isto posto, uma vez ser possível afirmar que, os professores são peças-chave nos processos formativos relacionados ao desenvolvimento de habilidades socioemocionais, na medida que são demandados atender a diversidade e, ao mesmo tempo, compreender e intervir nas necessidades dos alunos, sejam elas acadêmicas ou interpessoais. (Abed, 2016).

A prática baseada em evidências, inicialmente, pode ser concebida como uma abordagem com origem e grande aplicabilidade na área da Saúde. Abordagem esta que parte da definição de um problema, seguida da busca e validação de evidências disponíveis sobre determinado construto e/ou fenômeno. Além disto, busca elementos referentes à implementação de tais evidências, na prática, assim como a avaliação de possíveis resultados obtidos, em determinado contexto. Sendo assim, funciona como forma de obter, interpretar e integrar evidências oriundas de trabalhos 
científicos/pesquisas, com novos dados obtidos frente ao mesmo contexto, construto, fenômeno ou tema de investigação (Galvão \& Sawada, 2003).

Nos Estados Unidos, a centralidade das habilidades socioemocionais (Social and Emotional Learning-SEL), em estudos com implicações curriculares, tem impulsionado a implementação de ações educativas. Coelho et al. (2016) relatam que a SEL foi definida pelo The Collaborative for Academic, Social, and Emotional Learning (Casel) como processos nos quais os indivíduos (crianças e adultos) adquirem e aplicam, de forma eficaz, os conhecimentos, atitudes e competências necessárias para compreender e gerir suas próprias emoções, estabelecendo e atingindo objetivos positivos, estimulando relações positivas e tomando decisões responsáveis (Casel, 2012).

A Figura 01 exemplifica a estrutura de abordagem do Programa de desenvolvimento de habilidades socioemocionais The Collaborative for Academic, Social, and Emotional Learning:

Aprendizagem socioemocional

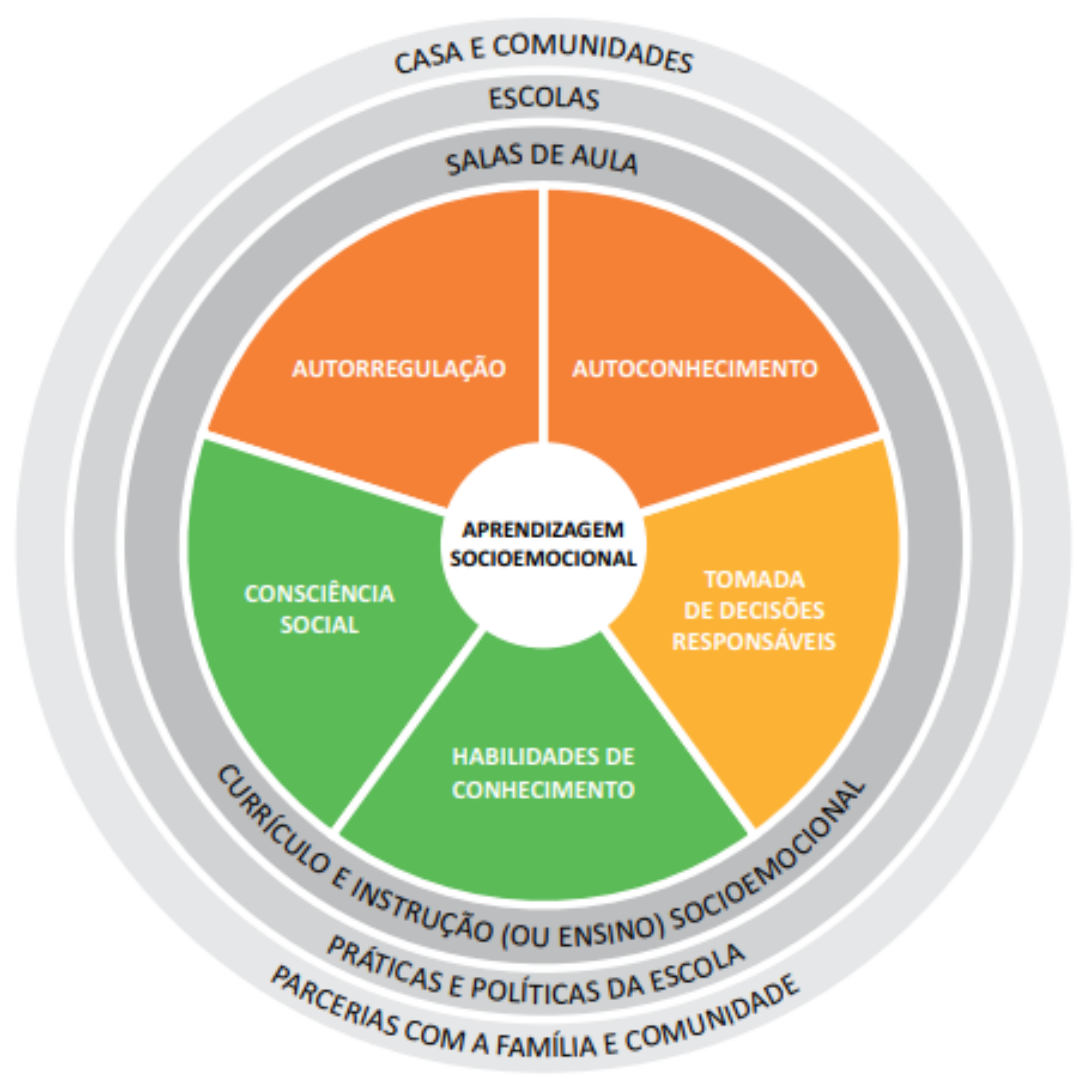

Figura 01: Casel - The Collaborative for Academic, Social, and Emotional Learning (recuperado de Colagrossi \& Vassimon, 2017, p.19).

Colagrossi \& Vassimon (2017) apresentam as principais habilidades socioemocionais definidas pelo Casel (2012) e preconizadas como as que deveriam ser aprendidas no contexto educacional:

- Autoconhecimento: capacidade de reconhecer as próprias emoções e pensamentos e como isso influencia o comportamento do sujeito. 
- Autorregulação: capacidade de regular as próprias emoções, pensamentos e comportamentos em diversas situações.

- Relacionamento Pessoal/Habilidades de Relacionamento: capacidade de estabelecer e manter relacionamentos saudáveis com diversos indivíduos e grupos.

- Consciência Social: capacidade de assumir a perspectiva do outro. Demonstrar empatia, incluindo aqueles de diversas origens e culturas.

- Tomada de Decisões Responsáveis: capacidade de fazer escolhas construtivas sobre comportamentos pessoais e interações sociais baseadas em padrões éticos, e normas sociais.

A SEL é framework educacional que valida o processo de desenvolvimento de tais habilidades para que seja possível atingir um nível satisfatório de competência socioemocional (Casel, 2017). Dessa forma, o destacado sobre os conceitos de competência socioemocional, desenvolvimento socioemocional e desempenho socioemocional, a partir de suas definições, abrangeriam o de habilidade socioemocional, acrescentando àqueles a noção de adequação do comportamento às demandas do contexto em que ele ocorre.

Nesse sentido, parece pertinente argumentar que o conceito e a forma como esse é apresentado e incorporado ao discurso educacional é de extrema relevância. Isto posto, uma vez que, no âmbito educacional contemporâneo, termos como habilidades socioemocionais, habilidades do século XXI, currículo socioemocional são cada vez mais frequentes e presentes nos documentos oficiais concernentes às políticas curriculares, especialmente com a Resolução CNE/CP n. ${ }^{\circ} 2$ que, aprovada em 22 de dezembro de 2017, institui uma Base Nacional Comum Curricular (BNCC) para a Educação Básica no Brasil.

A BNCC reafirma o que já vinha sendo aventado e prescrito em vários documentos regulatórios, como a Lei de Diretrizes e Bases da Educação Nacional (Brasil, 1996), as Diretrizes Curriculares Nacionais Gerais da Educação Básica (Brasil, 2013) e o Plano Nacional de Educação (Brasil, 2014) e por diversos autores como Coll (2010), ao expor a necessidade de compreender a ação educativa como um perspectiva de formação integral do sujeito: contemplando o desenvolvimento das habilidades cognitivas e não cognitivas, com destaque as socioemocionais.

O referido documento possui caráter normativo e apresenta uma lógica pautada no desenvolvimento de competências e habilidades, declarando compromisso com "aprendizagens sintonizadas com as necessidades, as possibilidades e os interesses dos estudantes e, também, com os desafios da sociedade contemporânea" (Brasil, 2017, p. 14). Em outras palavras, a formação no nível individual deve promover também uma integração na política educacional em direção ao avanço civilizatório. Os conceitos de autorregulação, empatia, resiliência, autoconhecimento, consciência social e outros trazem novas demandas e exigências para delineamentos curriculares. A perspectiva curricular deve ser consonante ao desenvolvimento de tais habilidades, bem como disponibilizar uma categorização geral das competências necessárias para seu atingimento, estruturadas em conhecimentos, valores e atitudes para promoção do desenvolvimento dos estudantes em todas as suas dimensões: intelectual, física, social, emocional e cultural (Brasil, 2017). Segundo Brasil (2017), as competências socioemocionais estão presentes em todas as 10 competências gerais, a saber, 1- Conhecimento; 2- Pensamento científico, crítico e criativo; 3 Repertório cultural; 4- Comunicação; 5- Cultura digital; 6- Trabalho e projeto de vida; 7Argumentação; 8- Autoconhecimento e autocuidado; 9- Empatia e cooperação e 10Responsabilidade e cidadania.

As competências gerais não são temas transversais, mas tem uma perspectiva ampla enquanto direitos essenciais a serem garantidos para cada um dos estudantes brasileiros como objetivo primordial da sua trajetória escolar. Assim como a BNCC tem caráter normativo e deve ser incorporada por todas as redes e instituições de ensino do país, as competências gerais também 
necessitam ser explicitadas nos currículos, projetos político-pedagógicos (PPP) e nas práticas cotidianas de gestores e professores. A inclusão de todos os agentes integrantes do processo educativo é imprescindível para a implementação de tais competências, na medida que: "não há concretização de objetivos de aprendizagem sem a consideração dos reais sujeitos de aprendizagem" (Brasil, 2017, p.33).

A instituição escolar e o currículo formal não escapam ilesos às modificações no mundo, especialmente da sua dimensão econômica, em sentido estrito. Tal influência é representada, por exemplo, pela influência da Organização para a Cooperação e Desenvolvimento Econômico (OCDE) no debate sobre habilidades socioemocionais. A educação é tida como grande vetor para o desenvolvimento econômico e tecnológico e diz respeito a uma diversidade de agentes sociais. O mesmo interesse é transferido para o desenvolvimento socioemocional quando esse caminha em direção a uma posição de centralidade no ideário educacional, nas práticas pedagógicas e no delineamento de currículos (Pacheco, 2003; Ciervo \& Silva, 2019).

A aprovação da BNCC também tornou a tecnologia digital uma competência "de ensino e para o ensino", que deve perpassar todas as áreas do conhecimento. E essa proposta não é algo novo ou inovador: é consenso dizer que as tecnologias educacionais digitais são o suporte contemporâneo para a propagação da informação e do conhecimento. A presença da tecnologia digital nas casas das pessoas e/ou nas escolas carrega uma outra dimensão: o acesso à tecnologia é um debate que diz respeito também a desigualdade social em uma perspectiva na qual o meio, a ferramenta educacional, tem relevância equiparável aos argumentos didáticos e filosóficos favoráveis ao seu uso. Os artefatos tecnológicos não são ferramentas neutras no cenário educacional e são influenciados pelos contextos sociais, não obstante, tal contestação não diminui a relevância da tecnologia enquanto componente essencial no desenvolvimento da atividade humana, e faz com que seja necessário um debate aprofundado, livre de dogmas e direcionado a política educacional (Pelgrum, 2001; Salomon, 2002; Amiel, Kubota \& Wives, 2016).

Com a popularização das tecnologias educacionais digitais no Brasil, principalmente a partir de 1995, houve uma tendência de pesquisa e ensino relacionada à chegada de hardwares e softwares nas escolas, impactando, em alguma medida, práticas e políticas educacionais. No final da década de 1990, as tecnologias digitais não substituíram o meio analógico (como especulavam alguns), mas reposicionaram a centralidade dos elementos necessários à alfabetização e letramento (em sentidos amplos e irrestritos), assim como pôs em xeque questões ligadas à cultura escrita impressa. (Ribeiro, 2016).

Nas duas décadas seguintes, a escola passou a ser cobrada por adequação a uma pedagogia requerida pelos nativos digitais, por formação de professores para incorporar tecnologias digitais em suas práticas, por instauração de uma cultura maker (incluindo atividades de programação e montagem de aparatos mecatrônicos) e por práticas de ensino que empreguem uso de dispositivos móveis em sala de aula, de sites, de ambientes virtuais de aprendizagem, blogs, redes sociais ou mesmo aplicativos como WhatsApp (Prensky, 2001; Veen \& Vrakking, 2009; Ribeiro, 2016). Recentemente tais requerimentos transitaram para a dimensão das políticas curriculares, em decorrência do estímulo deflagrado pela BNCC que, definindo diretriz curricular, atribui às tecnologias digitais um papel fundamental na implementação de uma cultura digital e de desenvolvimento de habilidades e competências, o que inclui as socioemocionais (Brasil, 2017; Ciervo \& Silva, 2019).

Feenberg (1999), expoente da Teoria Crítica da Tecnologia, defende que tecnologia é a mediadora da vida diária e que seus avanços e mudanças reverberam nas dimensões política, econômica, filosófica e cultural da sociedade, implicando necessidade de entendermos os domínios sociais e técnicos como unidade que compõe a existência humana e define os caminhos de uma sociedade democrática. Sendo assim, faz-se pertinente compreender como a tecnologia 
adentra o ambiente educacional: principal espaço de formação coletiva para a vida social de crianças e jovens.

As tecnologias digitais na educação, assim como habilidades socioemocionais, são construtos que se sobrepõem e orientam políticas com impacto direto na vida de estudantes e professores, e demandam respostas a contextos e racionalidades diversas que, por vezes, se apresentam como quebra-cabeças de difícil entendimento e sem espaços para consensos. A elucidação dos conceitos de tais construtos com vinculação crescente às políticas curriculares atuais, mapeando evidências acerca das relações entre habilidades socioemocionais e tecnologias educacionais, parece oportuno e adequado.

A ausência de revisões de literatura sobre a temática também indica uma lacuna na construção do conhecimento sobre a sobreposição entre as Tecnologias Educacionais e as Habilidades Socioemocionais. Para além de uma revisão exaustiva da literatura, a proposta deste artigo orienta-se para uma tentativa de caracterizar habilidades socioemocionais relacionadas às tecnologias educacionais baseada em evidências científicas.

\section{Objetivos}

\subsection{Objetivo Geral}

Este estudo tem por objetivo geral desenvolver uma revisão sistemática da literatura, relacionando Habilidades Socioemocionais e Tecnologias Educacionais a partir da ferramenta SUMMARIZE.

\subsection{Objetivos Específicos}

Identificar características apresentadas (autores, nome do estudo, ano, local, descrição dos participantes) pelos artigos selecionados. Identificar conceitos e/ou definições apresentadas nos artigos para Habilidades Socioemocionais (HSE) e Tecnologias Educacionais (TE). Identificar relações entre HSE e TE apresentadas em cada artigo selecionado.

\section{Método}

Inicialmente, destaca-se que foram tomados os cuidados éticos necessários, compreendidos em uma Revisão de Literatura de caráter sistemático, com o devido referenciamento dos trabalhos elencados e apresentados, assim como a descrição de todas as etapas realizadas durante a manufatura deste atual manuscrito. A revisão sistemática da literatura aqui proposta compreende etapas subsequentes e encadeadas, em um formato que se inspira no modelo sugerido por EPPICentre (2006) e replicado por Davies et al. (2013), além de: (a) integrar metodologia de síntese dos trabalhos proposta por Jabbour (2013) e (b) prover, ao final, um modelo com futuras perguntas de pesquisa direcionadas as lacunas encontradas na bibliografia (Dubey et al., 2017; Amui, Jabbour, Sousa Jabbour \& Kannan, 2017).

\subsection{Instrumento}

Como instrumento principal para a realização desta Revisão Sistemática de Literatura, utilizou-se a Plataforma Evidências - Módulo Sumarize (SUMARIZE, disponível em https://qeed.nees.com.br/). Esta é uma plataforma de acesso livre, a qual foi desenvolvida e implementada a partir da intersecção de pesquisadores e profissionais da área da Educação e da Tecnologia. Ela tem por objetivo, além de ser uma ferramenta adequada para a realização de revisões de literatura, agregar trabalhos que se insiram neste contexto e nesta forma, aproximando 
pesquisas e pesquisadores, destacando o potencial e relevância das pesquisas sendo feitas na área da Educação, no Brasil.

O SUMARIZE segue o preconizado como boas práticas para revisão de literatura, em grande parte pelo trabalho seminal de Kitchenham (2004), que tem como ponto principal o protocolo base para condução de Revisões Sistemáticas composto pelas seguintes etapas: I) Identificação de pesquisas, II) Seleção de estudos, III) Avaliação da qualidade dos estudos, IV) Extração de dados, V) Síntese de dados e VI) Relatórios.

Tais etapas, com algum ajuste terminológico, estão presentes em outras ferramentas orientadas a realização ou suporte da RSL tais como: State of the Art through Systematic Review - StArt (Oliveira \& Gomes 2015), webQDA (Souza, Costa \& Moreira, 2011), Systematic Review Automatic Tool - SRAT (Fabbri, Hernandes, Di Thommazo, Belgamo, Zamboni \& Silva, 2012) e a Ferramenta RESuLT (Cordova, 2017).

A Plataforma SUMARIZE concentra os principais pontos existentes em outras ferramentas, sendo seus principais recursos: a) integração de seu mecanismo de busca interno com as bases de dados acadêmicas existentes, b) ambiente controlado de iteração no qual os pesquisadores podem atuar de maneira recursiva na validação dos trabalhos e c) um sistema de reporte final claro e conciso, que fornece uma síntese aclarada dos trabalhos carregados na plataforma.

\subsection{Procedimentos}

\subsubsection{Definição colegiada dos descritores e protocolo PICOC}

A primeira etapa da Revisão Sistemática de Literatura, aqui desenvolvida, teve como desafio o recorte específico e a definição dos descritores a serem carregados nos mecanismos de busca e posteriormente no sistema SUMARIZE. Para tal, optou-se por uma abordagem de iterações em grupo, inspiradas tanto no desenho de pesquisa pautado nos grupos focais como em versões simplificadas de técnicas de elicitação de especialistas. Foram realizados dois grupos focais presenciais e três reuniões por videoconferência de acompanhamento e interação sobre o ajuste dos construtos, bases de dados e critérios. (Kitzinger, 1994; Wilkinson, 1998).

Tal abordagem tem forte apelo interdisciplinar, tendo sido utilizada em diversas áreas do conhecimento quando existe uma demanda por obtenção de opiniões qualificadas (best guess) acerca de questões que sob as quais ainda paira incerteza, no caso, a incerteza é fruto da falta de definição clara sobre os construtos a serem revisados. Essa abordagem tem o intuito de reduzir vieses na escolha dos construtos e ampliar o escopo da busca por meio da inserção de sinônimos e versões correlatas aos construtos indicados nas perguntas orientativas da revisão, conforme apresentado na Tabela 1 (Doria, Boyd, Tompkins \& Adger, 2009; Knol, Slottje, van der Sluijs \& Lebret, 2010; Morgan, 2014).

Tabela 1: Protocolo PICOC utilizado para a Revisão Sistemática de Literatura sobre Habilidades Socioemocionais e Tecnologias Educacionais.

\begin{tabular}{|c|c|}
\hline \multicolumn{2}{|c|}{ Protocolo PICOC } \\
\hline População & Educadores \\
\hline Intervenção & Tecnologias educacionais \\
\hline Comparação & N/A \\
\hline Resultados (Outcome) & Tecnologias educacionais; habilidades socioemocionais \\
\hline Contexto & Tecnologias educacionais; habilidades socioemocionais \\
\hline
\end{tabular}


$\mathrm{Na}$ etapa inicial foram carregadas as diretivas do Protocolo "PICOC", muito utilizado em estudos clínicos e que, não obstante precise ser ajustado para as especificidades das pesquisas no campo da educação, fornece bons parâmetros para o delineamento inicial do estudo.

\subsubsection{Estabelecimento de critérios de inclusão e exclusão}

Inicialmente, foram estabelecidos os critérios de inclusão:

a. a literatura deveria ter sido publicada entre 2009 e 2019;

b. necessariamente os artigos deveriam conter resumo;

c. o delineamento metodológico do trabalho deveria estar explicitado (mesmo que incompleto);

d. trabalhos acessíveis via web;

e. estudos primários relacionados ao uso da tecnologia digital e da informação e comunicação.

Já os critérios de exclusão estipulados foram:

a. estudos duplicados;

b. estudos que não contemplem a temática;

c. fora do contexto escolar.

Destaca-se que, inicialmente, como critério para inclusão nesta atual revisão, os trabalhos elencados deveriam ter sido realizados em contexto brasileiro. Porém, a partir das buscas iniciais, observou-se um número reduzido de achados, inviabilizando a busca, a partir dos descritores selecionados, pergunta de pesquisa e objetivos delineados. Sendo assim, a partir de reuniões e acordo entre os autores, optou-se pela inclusão de trabalhos realizados, dentro destes parâmetros, também em contexto internacional.

\subsubsection{Busca pelos estudos em bases distintas}

A seguir é apresentada a string geral adotada no presente trabalho, abarcando os construtos relevantes para a revisão e seus termos correlatos:

- ("Information and communication technology") AND ("soft skill*" OR "socioemotional skill*" OR "social emotional skill*" OR "socioemotional hability" OR "socioemotional habilities" OR "social emotional hability" OR "social emotional habilities" OR "social emotional competences" OR "social emotional competencies" OR "socioemotional competences" OR "socioemotional competencies") AND "Education".

- ("Tecnologia Digital da Informação e Comunicação" OR "Tecnologia da Informação e Comunicação") AND ("Habilidade socioemocional" OR "competência socioemocional").

Destaca-se que, ao longo da revisão, esta string foi adaptada (quando necessário), de acordo com as características específicas de cada base de dados.

\subsubsection{Triagem inicial: análise dos Títulos e Resumos dos trabalhos}

A triagem foi iniciada pela seleção das bases de dados e reformulação das strings, notou-se a necessidade de ampliar o espectro da busca através da adição de mais sinônimos. Foram encontrados 238 artigos nos buscadores, sendo que 25 foram aceitos após leitura dos resumos, verificação de acesso ao artigo e revisão por pares, conforme apresentado na Figura 02. 


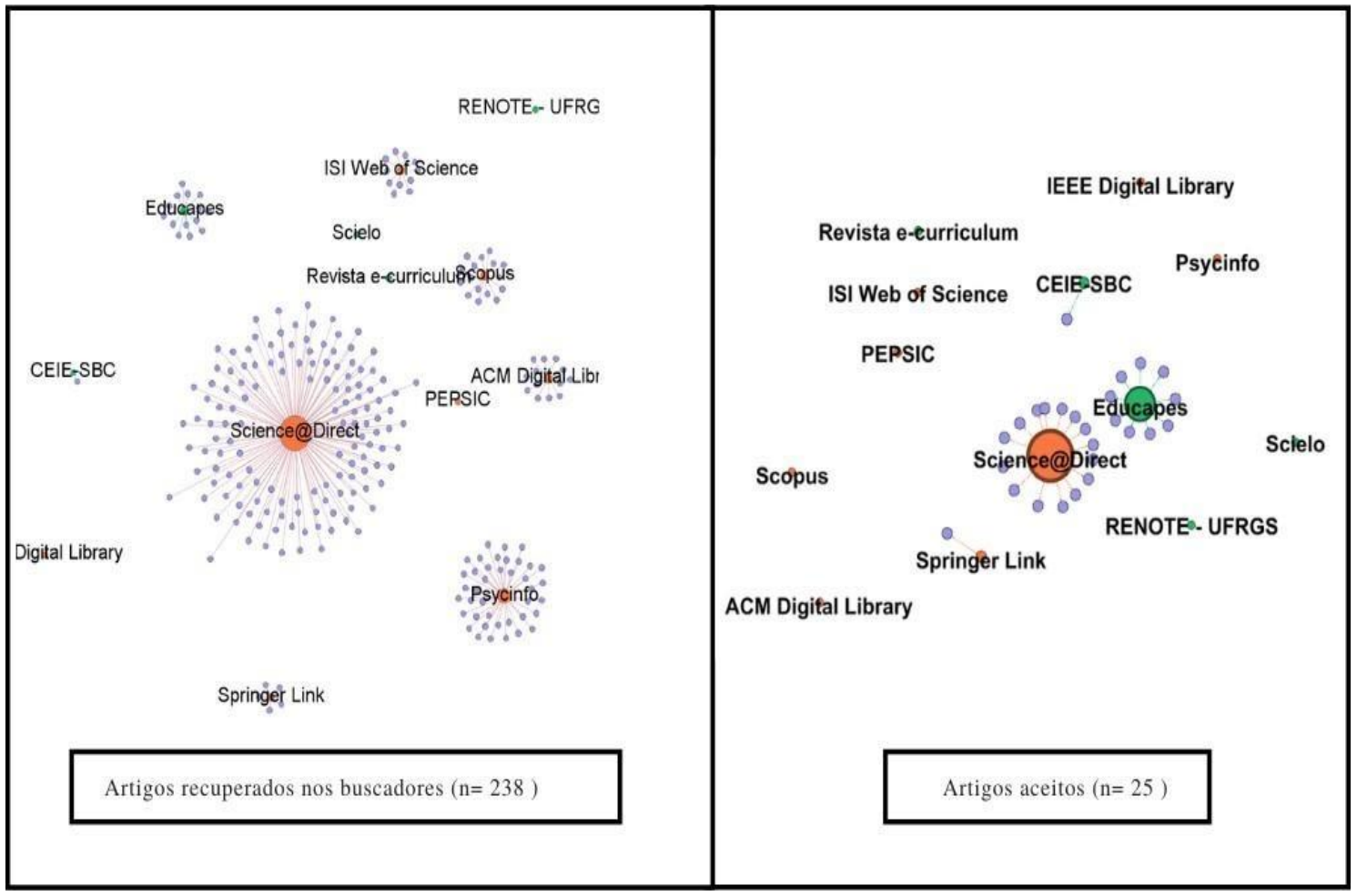

Figura 02: Variação no número de artigos por base de dados pré e pós leitura dos resumos (elaborado pelos autores).

Foi realizada uma leitura completa e aplicada a avaliação de qualidade aos 25 artigos, dos quais 15 foram excluídos. Por fim, dez (10) artigos foram aceitos para revisão sistemática, conforme demonstrado na Figura 03.

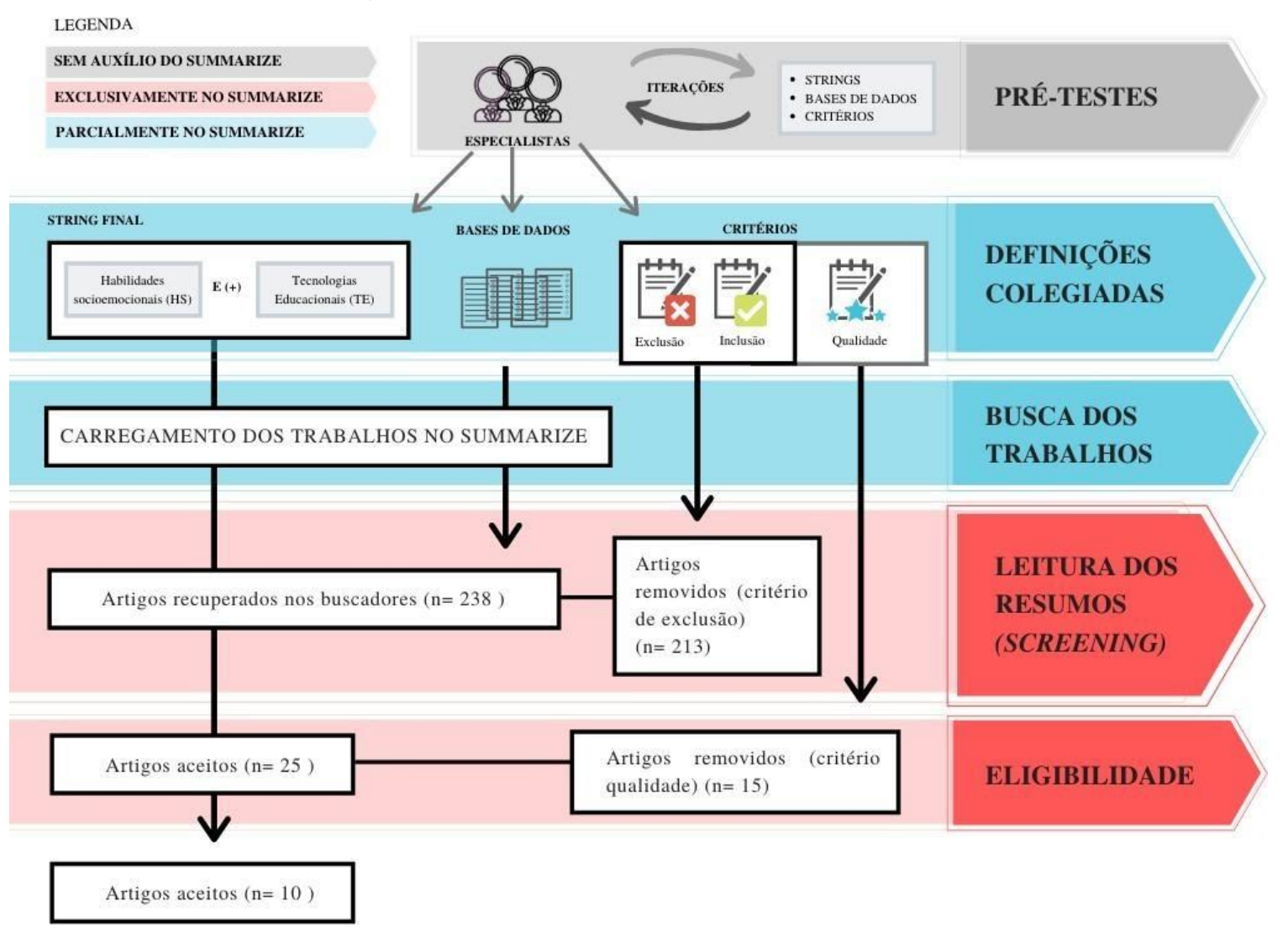

Figura 03: Quadro síntese das etapas da Revisão (elaborado pelos autores) 


\subsubsection{Síntese e mapeamento dos trabalhos}

A síntese dos artigos foi realizada tendo como referência a avaliação de qualidade, definida como base em uma nota de corte para aceitação ou não do trabalho. Foi definido um protocolo de perguntas balizadoras na qual a nota de corte foi 3,5. As respostas eram "sim", "parcialmente" e "não", que valiam respectivamente: 1,$0 ; 0,5 ; 0$. Sobre o critério de avaliação das perguntas: os estudos que definiram o conceito ou responderam a pergunta diretamente, obtiveram como resposta "sim"; para os estudos que definiram o conceito, responderam a pergunta indiretamente ou trabalharam com o conceito diretamente sem o definir, obtiveram como resposta "parcialmente"; por fim, os estudos que não responderam a pergunta ou não trabalharam com os conceitos, obtiveram como resposta "não".

Após a etapa de avaliação de qualidade, foi realizada uma etapa de extração de dados dos artigos, os quais estão descritos nos resultados. As perguntas norteadoras, assim como os pontos atribuídos na avaliação de qualidade desta atual Revisão estão apresentados, abaixo, na Figura 04.

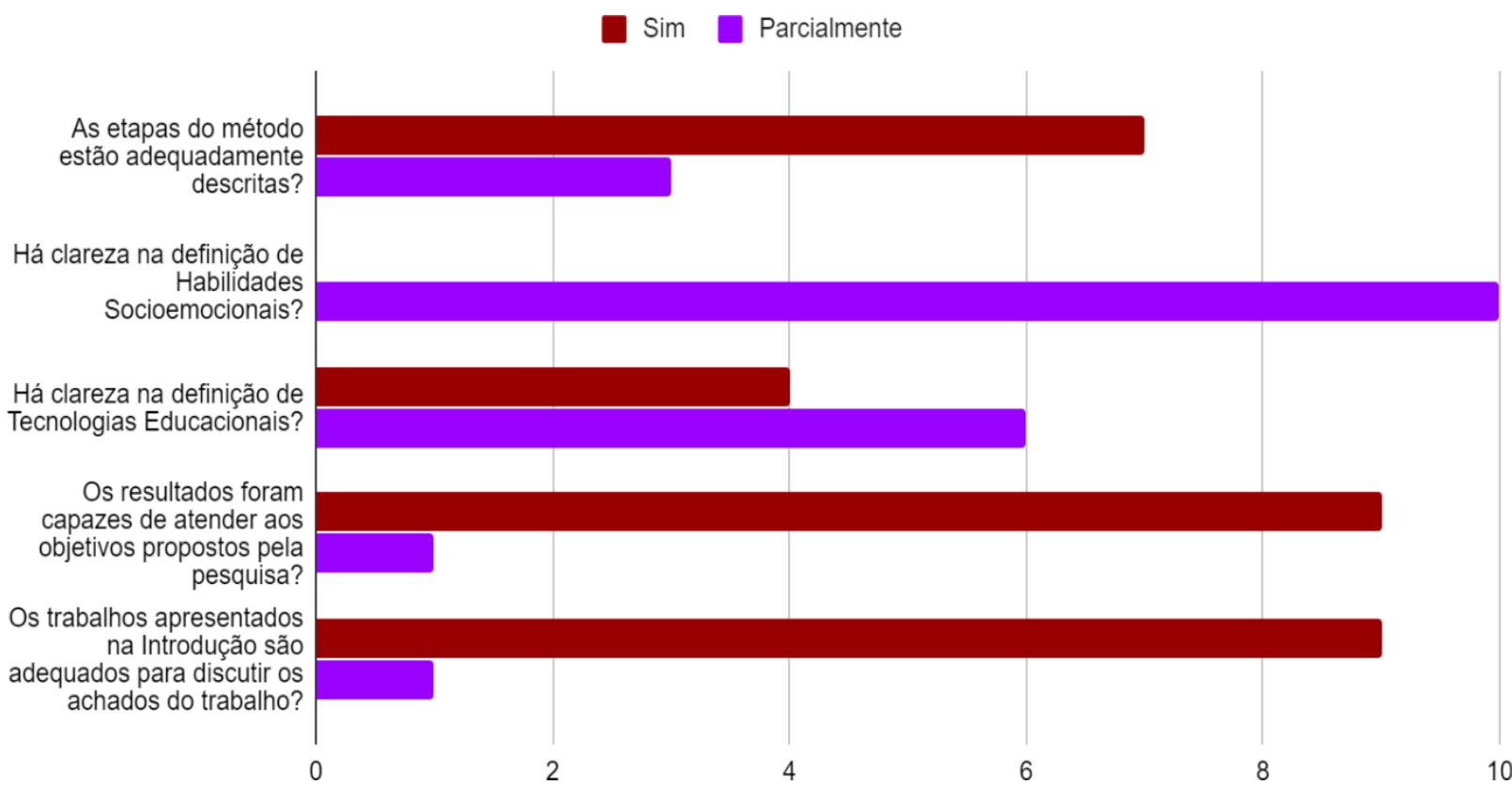

Figura 04: Quadro síntese da avaliação de qualidade (elaborado pelos autores)

O gráfico indicado na Figura 04 reflete a síntese da avaliação de qualidade dos trabalhos dez manuscritos finais: Bruns et al. (2018), Caroline et al. (2011), Huizenga et al. (2017), Kerkhoff (2017), Mertala (2017), Nakashima et al. (2015), Osman et al. (2010), Porat et al. (2018), Sabitzer (2013) e Schuepbach et al. (2009).

\section{Resultados e discussão}

Nesta seção serão apresentados os achados da Revisão Sistemática de Literatura em relação às Habilidades Socioemocionais e Tecnologias Educacionais. A Tabela 2 apresenta a síntese dos achados em cada um dos dez (10) trabalhos selecionados, assim como informações descritivas de cada estudo. 
Tabela 2: Descrição dos artigos selecionados (n=10), em relação ao país, participantes e síntese do trabalho.

\begin{tabular}{|c|c|c|c|c|}
\hline Autores & Título & País & $\begin{array}{c}\text { Participantes/contexto/Público } \\
\text { alvo }\end{array}$ & Síntese \\
\hline $\begin{array}{l}\text { Bruns et al. } \\
\quad(2018)\end{array}$ & $\begin{array}{l}\text { Through the } \\
\text { looking glass: } \\
\text { Can classroom } \\
\text { observation and } \\
\text { coaching } \\
\text { improve teacher } \\
\text { performance in } \\
\text { Brazil? }\end{array}$ & $\begin{array}{l}\text { Brasil } \\
\text { (estado } \\
\text { do } \\
\text { Ceará) }\end{array}$ & 292 escolas & $\begin{array}{c}\text { Foi realizada uma avaliação } \\
\text { randomizada de um programa } \\
\text { de treinamento baseado no } \\
\text { livro Teach like a Champion } \\
\text { de Douglas Lemov. A } \\
\text { intervenção consistiu em } \\
\text { observação da sala de aula, } \\
\text { materiais pedagógicos e } \\
\text { treinamento. }\end{array}$ \\
\hline $\begin{array}{l}\text { Caroline et } \\
\text { al. }(2011)\end{array}$ & $\begin{array}{l}\text { Design and } \\
\text { implementation } \\
\text { of a student- } \\
\text { generated virtual } \\
\text { museum in a } \\
\text { language } \\
\text { curriculum to } \\
\text { enhance } \\
\text { collaborative } \\
\text { multimodal } \\
\text { meaning- making }\end{array}$ & Singapura & $\begin{array}{c}78 \text { estudantes } \\
\text { em } 2009 \text { e } 80 \\
\text { em } 2010\end{array}$ & $\begin{array}{c}\text { O estudo consiste no design e } \\
\text { implementação de um museu } \\
\text { de realidade virtual, o MUSE, } \\
\text { em Singapura. Além disso, o } \\
\text { estudo conta com feedbacks de } \\
\text { alunos do } \\
\text { ensino fundamental através } \\
\text { de entrevistas } \\
\text { semiestruturadas sobre o } \\
\text { museu. }\end{array}$ \\
\hline $\begin{array}{c}\text { Huizenga et } \\
\text { al. (2017) }\end{array}$ & $\begin{array}{l}\text { Teacher perceptions } \\
\text { of the value of } \\
\text { game- based } \\
\text { learning in } \\
\text { secondary education }\end{array}$ & Holanda & $\begin{array}{c}43 \text { professores } \\
\text { (30 homens, } 13 \text { mulheres) }\end{array}$ & $\begin{array}{l}\text { A pesquisa se trata de uma } \\
\text { avaliação da percepção de } \\
\text { professores sobre o uso de } \\
\text { jogos para o aprendizado. Para } \\
\text { tal, foram realizadas entrevistas } \\
\text { semiestruturadas com } \\
\text { professores do ensino médio na } \\
\text { Holanda. }\end{array}$ \\
\hline $\begin{array}{l}\text { Kerkhoff } \\
(2017)\end{array}$ & $\begin{array}{l}\text { Designing global } \\
\text { futures: A mixed } \\
\text { methods study to } \\
\text { develop and } \\
\text { validate } \\
\text { the teaching for } \\
\text { global readiness } \\
\text { scale }\end{array}$ & EUA & $\begin{array}{c}630 \\
\text { participantes }\end{array}$ & $\begin{array}{l}\text { Este estudo utilizou um projeto } \\
\text { sequencial exploratório de } \\
\text { métodos mistos para validar a } \\
\text { escala teaching for global } \\
\text { readiness. O estudo focou nos } \\
\text { professores e se passou em } \\
\text { vários estados dos EUA. }\end{array}$ \\
\hline $\begin{array}{c}\text { Mertala } \\
(2017)\end{array}$ & $\begin{array}{l}\text { Wag the dog- } \\
\text { The nature and } \\
\text { foundations of } \\
\text { preschool } \\
\text { educators' } \\
\text { positive ICT } \\
\text { pedagogical } \\
\text { beliefs }\end{array}$ & Finlândia & $\begin{array}{c}17 \text { educadores } \\
\text { (4 diretores, } 2 \\
\text { vice diretores, } 8 \\
\text { professores, } 3 \text { enfermeiras) }\end{array}$ & $\begin{array}{l}\text { O estudo avalia as crenças } \\
\text { pedagógicas positivas e a } \\
\text { formação de professores em } \\
\text { relação às TICs na Finlândia. } \\
\text { Para isto, o estudo realiza } \\
\text { entrevistas com } 17 \\
\text { educadores, estes são: } 4 \\
\text { diretores, } 2 \text { vice diretores, } 8 \\
\text { professores e } 3 \text { enfermeiras. }\end{array}$ \\
\hline $\begin{array}{l}\text { Nakashima } \\
\text { et al. (2015) }\end{array}$ & $\begin{array}{l}\text { ProUCA-TO: } \\
\text { Espaço de } \\
\text { Construção de } \\
\text { Competências } \\
\text { Socioemocionais }\end{array}$ & $\begin{array}{c}\text { Brasil } \\
\text { (estado de } \\
\text { Tocantins) }\end{array}$ & $\mid \begin{array}{c}2.065 \text { cursistas entre professores } \\
\text { e gestores das escolas e uma } \\
\text { equipe de } 144 \text { formadores e } \\
\text { tutores }\end{array}$ & $\begin{array}{l}\text { O estudo apresenta um } \\
\text { projeto de formação que } \\
\text { ocorre no Estado de } \\
\text { Tocantins e envolveu } 135 \\
\text { escolas municipais de } 74 \\
\text { municípios. A formação } \\
\text { contemplou } 2065 \\
\text { profissionais da educação, } \\
\text { entre eles, professores, } \\
\text { gestores e tutores e teve a } \\
\text { intenção de possibilitar }\end{array}$ \\
\hline
\end{tabular}




\begin{tabular}{|c|c|c|c|c|}
\hline & & & & $\begin{array}{l}\text { inclusão digital escolar, } \\
\text { apropriação tecnológica e } \\
\text { pedagógica através de } \\
\text { laptops. }\end{array}$ \\
\hline $\begin{array}{l}\text { Osman et al. } \\
(2010)\end{array}$ & $\begin{array}{l}\text { Development and } \\
\text { validation of the } \\
\text { Malaysian } 21 \mathrm{st} \\
\text { century skills } \\
\text { instrument (M- } \\
\text { 21CSI) for } \\
\text { science } \\
\text { students }\end{array}$ & Malásia & $\begin{array}{c}760 \text { estudantes de escola } \\
\text { secundária }\end{array}$ & $\begin{array}{c}\text { O estudo desenvolveu e validou } \\
\text { a escala Malaysian } 21 \text { st Century } \\
\text { Skills Instrument (M-21CSI), } \\
\text { que investiga alfabetismo } \\
\text { digital, pensamento criativo, } \\
\text { comunicação efetiva entre } \\
\text { outros. O estudo foi realizado } \\
\text { nas escolas secundárias da } \\
\text { Malásia. }\end{array}$ \\
\hline $\begin{array}{l}\text { Porat et al. } \\
\quad(2018)\end{array}$ & $\begin{array}{l}\text { Measuring digital } \\
\text { literacies: Junior } \\
\text { high- school } \\
\text { students' } \\
\text { perceived } \\
\text { competencies } \\
\text { versus actual } \\
\text { performance }\end{array}$ & Israel & 280 estudantes & $\begin{array}{c}\text { O estudo investiga o } \\
\text { analfabetismo digital em } 280 \\
\text { estudantes do sétimo ano e } \\
\text { compara o analfabetismo } \\
\text { digital percebido e o } \\
\text { analfabetismo digital real em } \\
\text { escolas de Israel. Os alunos } \\
\text { realizaram testes digitais com o } \\
\text { tempo de } 90 \text { minutos, a fim de } \\
\text { avaliar o analfabetismo digital. }\end{array}$ \\
\hline $\begin{array}{l}\text { Sabitzer } \\
(2013)\end{array}$ & $\begin{array}{l}\text { Informatics meets } \\
\text { foreign languages } \\
\text { COOL ideas for a } \\
\text { cross-curricular } \\
\text { cooperation }\end{array}$ & Áustria & $\begin{array}{c}\text { Professores e duas turmas } \\
\text { com cerca } \\
\text { de } 60 \text { alunos cada }\end{array}$ & $\begin{array}{c}\text { O artigo propôs uma } \\
\text { ferramenta de ensino de língua } \\
\text { interativa com o intuito de } \\
\text { melhorar a didática e o } \\
\text { aprendizado: COOL } \\
\text { (COoperative Open Learning). } \\
\text { Essa ferramenta foi testada em } \\
\text { alunos de escola secundária na } \\
\text { Áustria. }\end{array}$ \\
\hline $\begin{array}{l}\text { Schuepbach } \\
\text { et al. (2009) }\end{array}$ & $\begin{array}{l}\text { Educating the } \\
\text { next generation } \\
\text { of atmospheric } \\
\text { scientists } \\
\text { within a } \\
\text { European } \\
\text { Network of } \\
\text { Excellence }\end{array}$ & $\begin{array}{l}\text { Grécia, } \\
\text { Letônia e } \\
\text { França }\end{array}$ & $\begin{array}{l}\text { professores, estudantes de } \\
12-18 \text { anos, e cientistas } \\
\text { recém-formados (até } 5 \text { anos } \\
\text { depois de completarem } \\
\text { mestrado ou doutorado) }\end{array}$ & $\begin{array}{c}\text { O estudo descreve como foi } \\
\text { desenvolvido e implementado } \\
\text { um Ambiente de } \\
\text { Aprendizagem Integrado } \\
\text { (AIE). O intuito desse ambiente } \\
\text { é ensinar a próxima geração de } \\
\text { cientistas atmosféricos sobre o } \\
\text { programa que eles chamam } \\
\text { ACCENT, que é uma } \\
\text { abreviação para European } \\
\text { Network of Excellence in } \\
\text { Atmospheric Composition } \\
\text { Change. }\end{array}$ \\
\hline
\end{tabular}

A síntese dos estudos permite observar um espectro diverso de abordagens que, não obstante estejam aqui aglutinadas dentro do escopo da revisão, apresentam-se heterogêneas. Nota-se também a amplitude de formas e usos de tecnologia educacional, e todas do tipo digital, tomada aqui como base e que transita de abordagens usuais como a dos ambientes virtuais de aprendizagem até a validação de escalas e treinamentos específicos para agentes educacionais. Para além disso, destaca-se o número reduzido de trabalhos realizados no Brasil.

Os trabalhados de pesquisadores brasileiros tratam de intervenções focadas no desenvolvimento de habilidades dos profissionais da área da educação (professores, gestores, etc.), onde a tecnologia educacional digital é apresentada como instrumento de formação ou inclusão, não havendo a explicitação da relação direta com as habilidades socioemocionais. Nos 
artigos internacionais, pelo previamente exposto na Tabela 2, o foco das investigações também recai em intervenções junto a profissionais da área da educação. Esse é um indicativo, portanto, de que as ações, nos contextos abordados por esta revisão, denotam esforços em preparar e sensibilizar os profissionais para o uso adequado de ferramentas tecnológicas (no âmbito educacional e no desenvolvimento de habilidades socioemocionais), ainda que o impacto nas relações com os estudantes seja foco secundário de interesse e/ou nem sempre um quadro teóricoconceitual, acerca de tecnologias e de habilidades socioemocionais, se faz presente.

Nesse sentido, a Tabela 3 apresenta, de acordo com os trabalhos levantados nesta revisão de literatura, definições de habilidade socioemocionais, correspondências com as habilidades socioemocionais preconizadas pelo Casel (2012) (Autoconhecimento, Autorregulação, Consciência Social, Relacionamento Pessoal/Habilidades de relacionamento e Tomada de Decisões Responsáveis) e/ou com a BNCC (Brasil, 2017) (Argumentação, Autoconhecimento e autocuidado; Comunicação; Conhecimento; Cultura Digital; Empatia e Cooperação; Pensamento Científico, Crítico e Criativo; Repertório Cultural; Responsabilidade e Cidadania; Trabalho e Projeto de Vida) e a tecnologia educacional que foi utilizada na investigação/intervenção.

Tabela 3: Definições de HSE, relação Casel - BNCC e tecnologia utilizada

\begin{tabular}{|c|c|c|c|}
\hline Autores & Conceitos e Definições de HSE & $\begin{array}{l}\text { Relação com Casel*/ } \\
\text { BNCC** }\end{array}$ & Tecnologia utilizada \\
\hline $\begin{array}{l}\text { Bruns et al. } \\
\quad(2018)\end{array}$ & $\begin{array}{l}\text { Não define os termos, mas cita } \\
\text { diretamente a expressão } \\
\text { "Habilidade Socioemocionais" }\end{array}$ & $\begin{array}{l}\text { Os autores trabalham } \\
\text { diretamente com a } \\
\text { expressão Habilidade } \\
\text { Socioemocional. }\end{array}$ & $\begin{array}{l}\text { Treinamentos via } \\
\text { Skype. }\end{array}$ \\
\hline $\begin{array}{l}\text { Caroline et } \\
\text { al. }(2011)\end{array}$ & $\begin{array}{l}\text { O trabalho descreve o objetivo do } \\
\text { museu virtual, relacionando-o ao } \\
\text { desenvolvimento de "identidades } \\
\text { culturais" dos estudantes como } \\
\text { cidadãos de Singapura. }\end{array}$ & $\begin{array}{c}\text { Consciência Social; } \\
\text { Conhecimento; } \\
\text { Cultura digital; } \\
\text { Repertório cultural; } \\
\text { Responsabilidade e } \\
\text { cidadania; }\end{array}$ & $\begin{array}{l}\text { MUSE, um museu } \\
\text { virtual interativo. }\end{array}$ \\
\hline $\begin{array}{l}\text { Huizenga et } \\
\text { al. (2017) }\end{array}$ & $\begin{array}{l}\text { O estudo menciona "soft skills" e } \\
\text { "communicative skills" como } \\
\text { consequência direta do uso de } \\
\text { jogos, mas não define os conceitos } \\
\text { diretamente. O estudo também faz } \\
\text { referência ao desenvolmento de } \\
\text { tipos de pensamentos que vão } \\
\text { além } \\
\text { do "aprendizado e pensamento } \\
\text { tradicional". }\end{array}$ & $\begin{array}{c}\text { Autorregulação; } \\
\text { Comunicação; } \\
\text { Consciência social; } \\
\text { Cultura digital; } \\
\text { Empatia e } \\
\text { colaboração; } \\
\text { Pensamento } \\
\text { científico, crítico e } \\
\text { criativo; } \\
\text { Tomada de decisões } \\
\text { responsáveis; }\end{array}$ & $\begin{array}{l}\text { Jogos digitais para } \\
\text { aprendizagem. }\end{array}$ \\
\hline $\begin{array}{l}\text { Kerkhoff } \\
(2017)\end{array}$ & $\begin{array}{l}\text { O artigo cita o conceito de "soft } \\
\text { skills", mas não o define. No texto } \\
\text { pode ser lida a defesa de quão } \\
\text { essencial é o } \\
\text { desenvolvimento do pensamento } \\
\text { crítico, criativo e a comunicação } \\
\text { intercultural. }\end{array}$ & $\begin{array}{c}\text { Autorregulação; } \\
\text { Comunicação; } \\
\text { Consciência Social; } \\
\text { Pensamento } \\
\text { Científico, Crítico e } \\
\text { Criativo; } \\
\text { Trabalho e projeto } \\
\text { de vida; }\end{array}$ & $\begin{array}{l}\text { Escala teaching for } \\
\text { global readiness. }\end{array}$ \\
\hline
\end{tabular}




\begin{tabular}{|c|c|c|c|}
\hline $\begin{array}{l}\text { Mertala } \\
(2017)\end{array}$ & $\begin{array}{l}\mathrm{O} \text { trabalho cita "socio-emotional } \\
\text { skills" e "socio-emotional well } \\
\text { being", destaca a sua importância, } \\
\text { mas não os define. }\end{array}$ & $\begin{array}{l}\text { Os autores trabalham } \\
\text { diretamente com a } \\
\text { expressão Habilidade } \\
\text { Socioemocional }\end{array}$ & $\begin{array}{c}\text { Não faz uso de } \\
\text { tecnologias diretamente, } \\
\text { mas tem como objetivo } \\
\text { investigar as crenças } \\
\text { pedagógicas positivas e a } \\
\text { formação de professores } \\
\text { em relação às } \\
\text { tecnologias da } \\
\text { informação e } \\
\text { comunicação. }\end{array}$ \\
\hline $\begin{array}{l}\text { Nakashima } \\
\text { et al. (2015) }\end{array}$ & $\begin{array}{l}\text { O artigo estabelece uma } \\
\text { relação direta entre o "big } 5 \text { ” } \\
\text { e as competências } \\
\text { socioemocionais, demonstra } \\
\text { a importância dessas, mas } \\
\text { não os define diretamente. }\end{array}$ & $\begin{array}{c}\text { Autoconhecimento; } \\
\text { Argumentação, } \\
\text { autoconhecimento e } \\
\text { autocuidado; } \\
\text { Autorregulação; } \\
\text { Empatia e cooperação; } \\
\text { Pensamento científico, } \\
\text { crítico e criativo; } \\
\text { Relacionamento } \\
\text { pessoal/habilidade de } \\
\text { relacionamento; } \\
\text { Responsabilidade e } \\
\text { cidadania; } \\
\end{array}$ & Laptops \\
\hline $\begin{array}{l}\text { Osman et al. } \\
\qquad(2010)\end{array}$ & $\begin{array}{l}\text { Com a validação da escala, o } \\
\text { estudo espera poder desenvolver o } \\
\text { pensamento crítico e a resolução } \\
\text { de problemas. O estudo também } \\
\text { demonstra de forma indireta que } \\
\text { seus resultados } \\
\text { são de importante consciência } \\
\text { social. A escala trabalha com } \\
\text { alfabetismo digital, pensamento } \\
\text { criativo e comunicação efetiva }\end{array}$ & $\begin{array}{l}\text { Autorregulação; } \\
\text { Comunicação; } \\
\text { Consciência social; } \\
\text { Cultura digital; } \\
\text { Pensamento científico, } \\
\text { crítico e criativo; } \\
\text { Tomada de decisões } \\
\text { responsáveis; }\end{array}$ & $\begin{array}{l}\text { Escala Malaysian 21st } \\
\text { century skills instrument } \\
\text { (M-21CSI) }\end{array}$ \\
\hline $\begin{array}{l}\text { Porat et al. } \\
\quad(2018)\end{array}$ & $\begin{array}{c}\text { O artigo parece indicar que o } \\
\text { analfabetismo digital prejudicaria } \\
\text { as habilidades sociais, entre } \\
\text { estas, cita as habilidades } \\
\text { socioemocionais, mas não as } \\
\text { define. Dentre os impactos no } \\
\text { analfabetismo digital, foi citado } \\
\text { relação direta } \\
\text { com tomadas de decisões e } \\
\text { habilidades de relacionamento, } \\
\text { mas sem especificar o que se } \\
\text { deveria entender sobre essas } \\
\text { habilidades. }\end{array}$ & $\begin{array}{l}\text { Cultura digital; } \\
\text { Conhecimento; } \\
\text { Relacionamento } \\
\text { pessoal/habilidade de } \\
\text { relacionamento; } \\
\text { Repertório cultural; } \\
\text { Tomada de decisões } \\
\text { responsáveis; }\end{array}$ & $\begin{array}{l}\text { O estudo não utiliza } \\
\text { diretamente uma } \\
\text { tecnologia, mas tem } \\
\text { como objetivo } \\
\text { investigar o alfabetismo } \\
\text { digital. }\end{array}$ \\
\hline $\begin{array}{l}\text { Sabitzer } \\
(2013)\end{array}$ & $\begin{array}{l}\text { O artigo trabalha com o conceito } \\
\text { de "soft- skills", mas não o define } \\
\text { diretamente. O COOL é baseado } \\
\text { no método de Helen Parkhurst, } \\
\text { que dentre as várias características } \\
\text { visa trabalhar independência, } \\
\text { responsabilidade, comunicação e } \\
\text { interação social. }\end{array}$ & $\begin{array}{c}\text { Comunicação; } \\
\text { Conhecimento; } \\
\text { Relacionamento } \\
\text { pessoal/habilidade de } \\
\text { relacionamento; } \\
\text { Repertório cultural; } \\
\text { Responsabilidade e } \\
\text { cidadania; } \\
\text { Trabalho e projeto de } \\
\text { vida; }\end{array}$ & $\begin{array}{l}\text { Uma ferramenta de ensino } \\
\text { de língua interativa com o } \\
\text { intuito de melhorar a } \\
\text { didática e o aprendizado: } \\
\text { COOL (COoperative } \\
\text { Open Learning). }\end{array}$ \\
\hline $\begin{array}{l}\text { Schuepbach } \\
\text { et al. (2009) }\end{array}$ & $\begin{array}{l}\text { O artigo trabalha com "soft- } \\
\text { skills", não define, mas faz } \\
\text { referência a dois exemplos do que }\end{array}$ & $\begin{array}{l}\text { Comunicação; } \\
\text { Conhecimento; } \\
\text { Consciência social; }\end{array}$ & $\begin{array}{l}\mathrm{O} \text { site ACCENT (the } \\
\text { European Network of }\end{array}$ \\
\hline
\end{tabular}




\begin{tabular}{|l|c|c|c|}
\hline & $\begin{array}{c}\text { seria o conceito: "comunicação e } \\
\text { liderança". Contudo, envolve o } \\
\text { desenvolvimento de tecnologias } \\
\text { educacionais para o ensino das } \\
\text { questões atmosféricas e explicita a } \\
\text { importância das mesmas. }\end{array}$ & $\begin{array}{c}\text { Cultura digital; } \\
\text { Trabalho e projeto de } \\
\text { vida; }\end{array}$ & $\begin{array}{c}\text { Excellence in Atmospheric } \\
\text { Composition Change) e } \\
\text { um Ambiente de }\end{array}$ \\
Aprendizagem Integrado. \\
$*$ *asel (2012) \\
$*$ BNCC (Brasil, 2017)
\end{tabular}

Uma análise da Tabela 3 mostra que, apesar das habilidades socioemocionais estarem relacionadas às temáticas dos trabalhos, a maioria dos artigos não define o construto diretamente. Há um espectro amplo de definições que poderiam ser relacionadas, direta ou indiretamente, a um quadro conceitual de habilidades socioemocionais proposto pela Casel (2012), a saber, 01 artigo se relaciona com autoconhecimento; 04 se relacionam com autorregulação; 04 artigos se relacionam com a consciência social; 03 artigos dizem respeito a relacionamento pessoal/habilidade de relacionamento e 03 artigos com tomada de decisões responsáveis.

Já em relação à BNCC (Brasil, 2017), verifica-se 01 artigo relacionado com argumentação, autoconhecimento e autocuidado; 05 artigos com comunicação; 04 artigos com conhecimento; 05 artigos com cultura digital; 02 artigos com empatia e cooperação; 04 artigos com pensamento científico, crítico e criativo; 03 artigos com Repertório Cultural; 03 artigos com responsabilidade e cidadania; 03 artigos com trabalho e projeto de vida. Dois dos artigos trabalham diretamente com o construto, mas não foi possível evidenciar explicitação de definições, conceitos ou mesmo uma simples elucidação acerca do que se deve entender sobre esses termos e/ou expressões.

Destaca-se também uma multiplicidade de usos de tecnologias digitais aplicadas para educação. Há uso de jogos, plataformas interativas, desenvolvimento de escalas e ferramentas digitais diversas. Tal multiplicidade demonstra que há formas diversas de aplicação das tecnologias digitais para educação na contemporaneidade e que o uso delas se faz presente em contextos que se relacionam a formas de desenvolvimento de habilidades socioemocionais.

Neste estudo, evidenciamos poucos trabalhos que relacionem habilidades socioemocionais e tecnologias educacionais. Dada a importância dessas e daquelas para o discurso educacional contemporâneo pode causar surpresa que não foram encontradas, dentro do escopo metodológico delineado, por exemplo, outras revisões sistemáticas que trabalhem com esse mesmo tema. Em relação à já mencionada ausência de definições e/ou discussões conceituais sobre habilidades socioemocionais nos trabalhos investigados, ressalta-se que essa pode ser uma amostra da falta de entendimentos, consensos e/ou diretrizes científicas sobre o conceito em questão. E isso, pode apresentar ressonâncias em contextos educacionais ao favorecer que interações limitadas ou parciais possam ser percebidas ou ditas como "habilidades socioemocionais".

Assim o sendo, a partir desta Revisão Sistemática de Literatura, destacam-se os seguintes pontos: i) um número reduzido de produções que abordem as relações entre o desenvolvimento de habilidades socioemocionais e uso de tecnologias educacionais; ii) uma pluralidade de termos e expressões, apresentando uma lacuna em termos de explicitação teórico-conceitual, relacionada a habilidades socioemocionais e tipos de tecnologias educacionais. Em decorrência, parece pertinente ressaltar a necessidade de avançar nas produções científicas acerca do uso das tecnologias educacionais, entendidas como ferramentas com potencial para investigar as habilidades socioemocionais, inclusive para além das intervenções.

Os achados deste estudo podem corroborar a crítica acerca de como o aumento da relevância do desenvolvimento de habilidades socioemocionais, presente nos discursos das políticas públicas educacionais (Abed, 2016; Marin \& Fava, 2016; Petrucci et al., 2016; Ciervo \& Silva, 2019), se deu de forma desarticulada dos avanços de investigações na área, reiterando o distanciamento entre o conhecimento acadêmico e cotidiano escolar. 


\section{Considerações Finais}

Diante do caráter inventariante e descritivo deste estudo, ressalta-se que esta é uma versão de determinada produção acadêmica, já que outras são possíveis (Garnica, 2013). Em suma, assumimos a possibilidade de existência de diferentes análises sobre determinada produção acadêmica e que esta revisão fornece uma delas, situada, ainda, na interpretação dos autores a partir do suporte da ferramenta SUMARIZE.

Este artigo pode frustrar a dinâmica das revisões de literatura que tem apoiado o desenvolvimento de pesquisas que esboçam tendências da produção acadêmica em geral, aglutinando similaridades e singularidades, e de pesquisas que demarcam limites conceituais e procedimentais muito específicos de uma área, permitindo fincar estacas caraterísticas e definidoras, de uma produção acadêmica em particular. Neste estudo, sobre Habilidades Socioemocionais relacionadas a Tecnologias Educacionais, mostra-se que, ao menos na área educacional representada pelos trabalhados investigados, lacunas se mostram constantes. E a respeito destas, especialmente, uma se faz muito presente: a falta de uma partilha com os leitores, por parte dos trabalhos investigados, de um quadro referencial em termos de definições e conceitos acerca do que se deve entender por Habilidades Socioemocionais.

Apontar uma lacuna como sendo um dos principais achados de uma pesquisa pode gerar, no mínimo, confusão. Porém, por outro lado, pode-se pensar que lacuna seja uma potencializadora, após a investigação, de mudanças de um contexto. No caso deste estudo, debruça-se sobre um contexto, ilustrado na maioria dos trabalhos investigados, no qual há investimentos em ações que envolvem o uso de tecnologias educacionais a favor de um "discurso socioemocional" o qual, apesar de relevante, se apresenta como frágil em relação às evidências científicas (conceituais e metodológicas) que deveriam sustentá-lo. Entende-se que tais evidências viabilizariam a necessária aproximação entre a produção científica e o cotidiano educacional. Sendo assim, estudos dessa natureza, com definição clara dos construtos teórico-epistemológicos envolvidos, não só são pertinentes, como são urgentes.

\section{Referências}

Abed, A. L. Z. (2016). O desenvolvimento das habilidades socioemocionais como caminho para a aprendizagem e o sucesso escolar de alunos da educação básica. Construção psicopedagógica, 24(25), 8-27. Recuperado de: http://pepsic.bvsalud.org/pdf/cp/v24n25/02.pdf. [GS Search]

Amiel, T., Kubota, L., \& Wives, W. (2016). A systemic model for differentiating school technology integration. Research in Learning Technology, 24. doi: $\underline{10.3402 / r l t . v 24.31856}$ [GS Search]

Amui, L. B. L., Jabbour, C. J. C., Sousa Jabbour, A. B. L., \& Kannan, D. (2017). Sustainability as a dynamic organizational capability: a systematic review and a future agenda toward a sustainable transition. Journal of Cleaner Production, 142, 308-322. doi: 10.1016/j.jclepro.2016.07.103 [GS Search]

Bolsoni-Silva, A. T. (2002). Habilidades sociais: breve análise da teoria e da prática à luz da análise do comportamento. Interação em Psicologia, 6(2), 233-242. doi: 10.5380/psi.v6i2.3311 [GS Search] 
Brasil (2017). Base Nacional Comum Curricular - Educação é a Base. Brasília, DF. Recuperado de:http://basenacionalcomum.mec.gov.br/images/BNCC_EI_EF_110518_versaofinal_site.p df. [GS Search]

(2014). Senado Federal. Plano Nacional de Educação. Brasília, DF. Recuperado de: http://fne.mec.gov.br/images/doc/pne-2014-20241.pdf.

(2013). Conselho Nacional de Educação. Diretrizes Curriculares Nacionais da Educação Básica. Brasília, DF. Recuperado de: http://portal.mec.gov.br/index.php?option=com_content\&id=12992.

(1996). Ministério da Educação. Lei de Diretrizes e Bases da Educação Nacional. Lei no 9.394, de 20 de dezembro de 1996. Recuperado de: http://portal.mec.gov.br/arquivos/pdf/ldb.pdf.

Caballo, V.E. (2014). Manual de técnicas de terapia e modificação do comportamento. São Paulo: Santos. [GS Search]

CASEL -The Collaborative for Academic, Social and Emotional Learning. Recuperado de: casel.org.

Ciervo, T., \& Silva, R. (2019). A centralidade das competências socioemocionais nas políticas curriculares contemporâneas no Brasil. Revista e-Curriculum, 17(2), 382-401. doi: 10.23925/1809-3876.2019v17i2p382-401. [GS Search]

Coll, C. et al. (2010). Psicologia da educação virtual: aprender e ensinar com as tecnologias da informação e da comunicação. Porto Alegre: Artmed, 366 p. [GS Search]

Coelho, V. A., Marchante, M., Sousa, V., \& Romão, A. M. (2016). Programas de intervenção para o desenvolvimento de competências socioemocionais em idade escolar: Uma revisão crítica dos enquadramentos SEL e SEAL. Análise Psicológica, 34(1), 61-72. doi: 10.14417/ap.966 [GS Search]

Colagrossi, A. L. R., \& Vassimon, G. (2017). A aprendizagem socioemocional pode transformar a educação infantil no Brasil. Construção psicopedagógica, 25(26), 17-23. Recuperado de: http://pepsic.bvsalud.org/pdf/cp/v25n26/03.pdf. [GS Search]

Collaborative for Academic, Social, and Emotional Learning (Casel, 2012). Casel guide: Effective social and emotional learning programs - Preschool and elementary school edition. Chicago, IL: R. P. Weissberg, Goren, C. Domitrovich, \& L. Dusenbury.

Cordova, E. N. (2017). Evolução da Ferramenta RESuLT para Auxiliar a Execução de Revisões Sistemáticas da Literatura. Universidade Federal De Santa Catarina. Florianópolis. [GS Searchl

Davies, D., Jindal-Snape, D., Collier, C., Digby, R., Hay, P., \& Howe, A. (2013). Creative learning environments in education-A systematic literature review. Thinking skills and creativity, 8, 80-91. doi: 10.1016/j.tsc.2012.07.004 [GS Search]

Del Prette, A., \& Del Prette, Z. A. P. (2003). Aprendizagem socioemocional na infância e prevenção da violência: questões conceituais e metodologia da intervenção. In A. Del Prette \& Z. A. P. Del Prette (Eds), Habilidades sociais, desenvolvimento e aprendizagem: questões conceituais, avaliação e intervenção (pp. 83-128). Campinas: Alínea. [GS Search]

Del Prette, Z. A. P., \& Del Prette, A. (1999). Psicologia das habilidades sociais: terapia e educação.Petrópolis: Vozes. [GS Search] 
Doria, M.F., Boyd, E., Tompkins, E. L., \& Adger, W. N. (2009). Using expert elicitation to define successful adaptation to climate change. Environmental Science \& Policy, 12(7), 810-819. doi: 10.1016/j.envsci.2009.04.001 [GS Search]

Dubey, R., Gunasekaran, A., Childe, S. J., Papadopoulos, T., \& Fosso Wamba, S. (2017). World class sustainable supply chain management: critical review and further research directions. The InternationalJournal of Logistics Management, 28(2), 332-362. doi: 10.1108/IJLM-072015-0112 [GS Search]

EPPI-CENTRE (2006). EPPI-Centre methods for conducting systematic reviews. Recuperado de: http://pblevaluation.pbworks.com/w/file/fetch/14976232/EPPI-

Centre_Review_Methods_1.pdf.

Fabbri, S., Hernandes, E. M., Di Thommazo, A., Belgamo, A., Zamboni, A., \& Silva, C. (2012). Managing literature reviews information through visualization. In ICEIS (2) (pp. 36-45). [GS $\underline{\text { Searchl }}$

Feenberg, A. (1999). Questioning technology. London and New York: Routledge, 1999. [GS $\underline{\text { Searchl }}$

Galvão, C. M., \& Sawada, N. O. (2003). Prática baseada em evidências: estratégias para sua implementação na enfermagem. Revista Brasileira de Enfermagem, 56(1), 57-60. doi: 10.1590/S0034-71672003000100012 [GS Search]

Garnica, A. V. M (2013). História Oral e Educação Matemática. In: M. C. Borba; J. L. Brandão (Ed.). Pesquisa Qualitativa em Educação Matemática. (pp.87-110). 5. ed. Belo Horizonte: Autêntica.

Jabbour, C. J. C. (2013). Environmental training in organisations: From a literature review to a framework for future research. Resources, Conservation and Recycling, 74, 144-155. doi: 10.1016/j.resconrec.2012.12.017 [GS Search]

Kitchenham, B. (2004). Procedures for performing systematic reviews. Keele, UK, Keele University, 33(2004), 1-26. Recuperado de: http://www.it.hiof.no/ haraldh/misc/2016-0822-smat/Kitchenham-Systematic-Review-2004.pdf. [GS Search]

Kitzinger, J. (1994). The methodology of focus groups: the importance of interaction between research participants. Sociology of health \& illness, 16(1), 103-121. Recuperado de: https://onlinelibrary.wiley.com/doi/pdf/10.1111/1467-9566.ep11347023.

Knol, A. B., Slottje, P., van der Sluijs, J. P., \& Lebret, E. (2010). The use of expert elicitation in environmental health impact assessment: a seven step procedure. Environmental Health, 9(1), 1-16. Recuperado de: http://www.ehjournal.net/content/9/1/19. [GS Search]

Lopez, M. (2008). La integración de las habilidades sociales en la escuela como estrategia para la salud emocional. Revista Electrónica de Intervención Psicosocial y Psicología Comunitaria, 3(1), 16-19. [GS Search]

Marin, A. H., \& Fava, D. C. (2016). Programas de intervenção no contexto escolar:revisão da literatura científica. In D. C. Fava (Ed), A prática da psicologia na escola: introduzindo a abordagem cognitivo-comportamental (pp. 325-350). Belo Horizonte: Ed. Artesã. [GS $\underline{\text { Search }]}$

McClelland, M. M., Tominey, S. L., Schmitt, S. A., \& Duncan, R. (2017). SEL interventions in early childhood. The Future of Children, 27(1) 33-47. Recuperado de: https://www.jstor.org/stable/pdf/44219020.pdf. 
Morgan, M. G. (2014). Use (and abuse) of expert elicitation in support of decision making for public policy. Proceedings of the National academy of Sciences, 111(20), 7176-7184. doi: 10.1073/pnas.1319946111. [GS Search]

Oliveira, F., \& Gomes, A. S. (2015). Uma revisão sistemática da literatura sobre ferramentas de autoria de IMS-LD. In Brazilian Symposium on Computers in Education (Simpósio Brasileiro de Informática na Educação-SBIE) (Vol. 26, No. 1, p. 376). doi: 10.5753/cbie.sbie.2015.376 [GS Search]

Pacheco, J. A. (2003). Políticas Curriculares: referenciais para análise. Porto Alegre: Artmed. [GS Search]

Pelgrum, W.J. (2001). Obstacles to the integration of ICT in education: results from a worldwide educational assessment. Computers \& Education, 37(2), 163-178. doi: 10.1016/S03601315(01)00045-8 [GS Search]

Petrucci, G. W., Borsa, J. C., \& Koller, S. H. (2016). A Família e a escola no desenvolvimento socioemocional na infância. Temas em Psicologia, 24(2), 391-402. Recuperado de: https://www.redalyc.org/service/redalyc/downloadPdf/5396/539656645001/8. [GS Search]

Prensky, M. (2001). Nativos digitais, imigrantes digitais. On the horizon, 9(5), 1-6. Recuperado de: $\quad$ http://blog.portalpositivo.com.br/matematicaspe/files/2016/02/texto-de-nativosdigitais_marc-presnky.pdf. [GS Search]

Ribeiro, A. E. (2016). Tecnologia digital e ensino: breve histórico e seis elementos para a ação. Revista Linguagem \& Ensino, 19(2), 91-111. Recuperado de: https://periodicos.ufpel.edu.br/ojs2/index.php/rle/article/viewFile/15260/9450. [GS Search]

Salomon, G. (2002). Technology and pedagogy: Why don't we see the promised revolution? Educational Technology, 42(2) 71- 75. Recuperado de: https://www.jstor.org/stable/44428740. [GS Search]

Souza, F. N., Costa, A. P., \& Moreira, A. (2011). Análise de dados qualitativos suportada pelo software webQDA. In Atas da VII Conferência Internacional de TIC na Educação: Perspetivas de Inovação (pp. 49-56). [GS Search]

Veen, W. \& Vrakking, B. (2009). Homo Zappiens: educando na era digital. Trad. de Vinícius Figueira. Porto Alegre: Artmed. [GS Search]

Wilkinson, S. (1998). Focus group methodology: a review. International journal of social research methodology, 1(3), 181-203. doi: 10.1080/13645579.1998.10846874 [GS Search] 